\title{
Miscarriage Risk in COVID-19 Infection
}

\author{
Tze Cheng Wong $^{1}$ (D) Zhi Yuan Lee ${ }^{1} \cdot$ Tonnii L. L. Sia $^{2} \cdot$ Andrew K. W. Chang ${ }^{2} \cdot$ Hock Hin Chua $^{2}$
}

Accepted: 6 August 2020 / Published online: 15 August 2020

(C) Springer Nature Switzerland AG 2020

Dear Editor,

The COVID-19 outbreak, which has its first reported case in Wuhan City, China, has evolved rapidly and was declared as a pandemic by the World Health Organization on 11 March 2020. The novel coronavirus is known officially as SARS-CoV-2. Genomic analysis revealed that SARS-CoV-2 is phylogenetically related to SARS-like bat viruses; therefore, bats could be the possible primary reservoir. Infected individuals have a broad spectrum of manifestations, ranging from asymptomatic and mild symptoms to severe disease with multiorgan involvement. Symptomatic patients commonly presented with fever, cough, shortness of breath and other non-specific symptoms such as muscle ache, headache, confusion and diarrhoea.

The implications of COVID-19 infection during pregnancy remain unclear at this moment. Pregnancy is considered high risk as this population remains vulnerable to coronavirus infection. Till date, data regarding SARS-CoV-2 infection amongst pregnant women, their manifestations and outcomes remain limited. Most pregnancies had good outcomes, and transmission of SARS-CoV-2 to infant was uncommon [1].

This article is part of the Topical Collection on COVID-19

Tze Cheng Wong

tchengwong91@hotmail.com

Zhi Yuan Lee

jameslee19900628@gmail.com

Tonnii L. L. Sia

tonnii_sia@yahoo.com

Andrew K. W. Chang

andrchang@gmail.com

Hock Hin Chua

hhchua2009@gmail.com

1 Department of Medicine, Sarawak General Hospital, Jalan Hospital, 93586 Kuching, Sarawak, Malaysia

2 Infectious Disease Unit, Department of Medicine, Sarawak General Hospital, Kuching, Sarawak, Malaysia
However, the relationship between SARS-CoV-2 infection and risk of miscarriage remains unclear.

Sarawak General Hospital is the only tertiary hospital in southern Sarawak, Malaysia, serving a population of around 2.5 million people. We have in total 465 SARSCoV-2 RT-PCR confirmed COVID-19 cases which were from 12 March 2020 to 25 May 2020. We use nasopharyngeal and oropharyngeal combined swab (NPS/OPS) to collect the samples for SARS-CoV-2 RT-PCR. Seven of these cases were pregnant women, in which at the time of presentation, 2 were in the first trimester, 3 in the second trimester and another 2 in the third trimester of their pregnancies. Two of the cases who were in their first trimester of pregnancies had miscarriages. At the time of writing, the other 5 cases have no reported adverse pregnancy outcomes, in which one of the cases has undergone an uneventful delivery through caesarean section.

We would like to highlight 2 cases of first trimester miscarriage in COVID-19 infected pregnant mothers.

The first case involves a 34-year-old Malay lady, who was gravida 5, para 4 at a 10-week period of amenorrhea when she was diagnosed to have COVID-19 infection. She first experienced irregular cramping lower abdominal pain, with per vaginal bleeding, associated with blood clots at a 7-week and 1day period of amenorrhea. Three days later, she started to experience non-productive cough and sore throat, which completely resolved after 2 days. She otherwise did not experience any fever, rhinorrhoea, shortness of breath, arthralgia, myalgia, anosmia, dysgeusia or any gastrointestinal symptoms. Her COVID-19 screening was around 2 weeks after a significant contact history with a colleague with COVID-19 infection, and her NPS/OPS for SARS-CoV-2 RT-PCR was positive.

Her blood investigations showed absolute lymphocyte count (ALC) $2.4 \times 10^{3} / \mu 1$, with total white cell (TWC) $11.18 \times 10^{3} / \mu 1$, platelet $397 \times 10^{3} / \mu$ land haemoglobin $(\mathrm{Hb})$ $13.3 \mathrm{~g} / \mathrm{dL}$. Renal profile and liver function test revealed no abnormality (Table 1). Chest X-ray was done and showed no active lung lesion (Fig. 1). Rapid antibody test was negative for both IgM and IgG SARS-CoV-2 antibodies. 
Table 1 Blood investigation results for case 1

\begin{tabular}{|c|c|c|c|c|c|}
\hline Date (2020) & April 16 & April 17 & April 18 & April 23 & April 24 \\
\hline $\mathrm{Hb}(\mathrm{g} / \mathrm{dL})$ & 13.3 & 12.9 & 13.3 & 12.4 & 12.3 \\
\hline TWC $\left(10^{3} / \mu \mathrm{L}\right)$ & 11.18 & 9.29 & 11.18 & 8.52 & 11 \\
\hline $\operatorname{PLT}\left(10^{3} / \mu \mathrm{L}\right)$ & 397 & 366 & 397 & 360 & 371 \\
\hline Lymph \# $\left(10^{3} / \mu \mathrm{L}\right)$ & 2.4 & 3.5 & 2.4 & 3.26 & 4.08 \\
\hline Mono \# $\left(10^{3} / \mu \mathrm{L}\right)$ & 8.05 & 0.6 & 0.38 & 0.37 & 0.49 \\
\hline Neu \# $\left(10^{3} / \mu \mathrm{L}\right)$ & 0.38 & 4.56 & 8.05 & 4.43 & 8.9 \\
\hline $\mathrm{Na}(\mathrm{mmol} / \mathrm{L})$ & 137 & 138 & 137 & 137 & \\
\hline $\mathrm{K}(\mathrm{mmol} / \mathrm{L})$ & 4.7 & 4.9 & 4.7 & 4.9 & \\
\hline $\mathrm{Cl}(\mathrm{mmol} / \mathrm{L})$ & 98 & 99 & 98 & 98 & \\
\hline Urea $(\mathrm{mmol} / \mathrm{L})$ & 3.3 & 2.9 & 3.3 & 2.6 & \\
\hline Creatinine $(\mu \mathrm{mol} / \mathrm{L})$ & 58 & 55 & 58 & 64 & \\
\hline $\mathrm{TB}(\mu \mathrm{mol} / \mathrm{L})$ & 8 & 7 & 8 & 6 & \\
\hline $\mathrm{DB}(\mu \mathrm{mol} / \mathrm{L})$ & 3.2 & 2.2 & 3.2 & 1.8 & \\
\hline $\operatorname{AST}(\mathrm{U} / \mathrm{L})$ & 14 & 14 & 14 & 14 & \\
\hline $\operatorname{ALT}(\mathrm{U} / \mathrm{L})$ & 9 & 9 & 9 & 8 & \\
\hline $\mathrm{TP}(\mathrm{g} / \mathrm{L})$ & 85 & 78 & 85 & 77 & \\
\hline Alb $(g / L)$ & 48 & 46 & 48 & 48 & \\
\hline Glob (g/L) & 37 & 32 & 37 & 29 & \\
\hline $\operatorname{ALP}(\mathrm{U} / \mathrm{L})$ & 60 & 56 & 60 & 54 & \\
\hline $\mathrm{LDH}(\mathrm{U} / \mathrm{L})$ & 351 & 345 & 351 & 437 & \\
\hline CPK (U/L) & 80 & 73 & 80 & 64 & \\
\hline CKMB (U/L) & & & 21 & & \\
\hline $\mathrm{PT}(\mathrm{s})$ & & & & 13 & \\
\hline INR & & & & 0.9 & \\
\hline APTT (s) & & & & 39 & \\
\hline
\end{tabular}

She was prescribed with hydroxychloroquine $400 \mathrm{mg}$ BD for 1 day and $200 \mathrm{mg}$ BD for another 4 days, which completed in a total of 5 days of treatment. She was managed conservatively and passed out product of conception 27 days after onset of symptoms.

The second case involves a 38-year-old Chinese lady, primigravida, who is at a 12-week period of amenorrhea when she was diagnosed to have COVID-19 infection. One week prior to her diagnosis of COVID-19, she experienced occasional, minimal per vaginal bleeding without any passing of blood clot. She was otherwise asymptomatic. She was screened for COVID-19 as part of a policy of a private medical centre prior to entry to their premises. Her rapid antibody test for SARS-CoV-2 showed positive IgG and negative IgM. This was followed by NPS/OPS for SARS-CoV-2 RT-PCR which was positive as well. She was referred to our centre for further management.

Her blood investigations showed ALC $1.63 \times 10^{3} / \mu 1$, with TWC of $8.89 \times 10^{3} / \mu$ l, platelet $299 \times 10^{3} / \mu \mathrm{l}$ and $\mathrm{Hb}$ $15.2 \mathrm{~g} / \mathrm{dL}$. Renal profile and liver function test revealed no abnormality (Refer Table 2). Chest radiograph (CXR) was normal (Fig. 2).

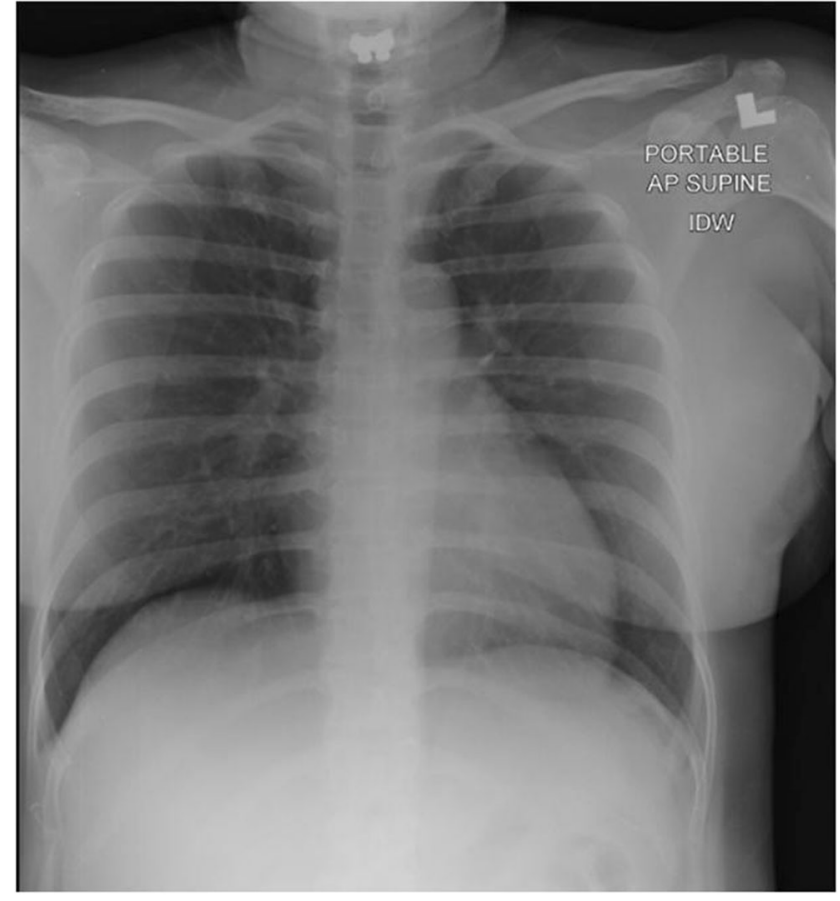

Fig. 1 Chest X-ray for case 1 on 17 April 2020 - no active lung lesion

No medication was started for her as she remains asymptomatic throughout her hospitalization. She has subsequently undergone surgical evacuation of retained product of conception.

Over the past 2 decades, 3 major coronavirus outbreaks have taken place, namely, the severe acute respiratory syndrome (SARS) caused by SARS-CoV in 2003, the Middle Eastern respiratory syndrome (MERS) caused by MERSCoV in 2012 and the current COVID-19 outbreak caused by SARS-CoV-2 which started since the end of December 2019. Information regarding pregnancy outcomes, particularly first trimester miscarriage, remains limited. There was no reported data on miscarriage for COVID-19 infection occurring during the first trimester [2]. SARS-CoV infection during pregnancy was associated with high incidences of spontaneous miscarriage, preterm delivery and intrauterine growth restriction. MERS-CoV infection might pose serious health risks to both mothers and infants during pregnancy, although further data is needed to define the apparent association [3].

The first case suffered from a mild COVID-19 infection, with minimal respiratory symptoms 3 days prior to the onset of per vaginal bleeding. Throughout her illness, she remained stable, with no clinical progression to severe disease. The second case has an asymptomatic course of COVID-19 infection, which was diagnosed incidentally as a requirement policy for admission into a private medical centre.

For both cases, the duration between possible exposure to SARS-CoV-2 until the day of miscarriage was relatively unknown, but there was evidence that the COVID-19 infection likely occurred earlier or around the time of miscarriage. For 
Table 2 Blood investigation results for case 2

\begin{tabular}{|c|c|c|c|c|}
\hline Date (2020) & April 19 & April 23 & May 5 & May 9 \\
\hline $\mathrm{Hb}(\mathrm{g} / \mathrm{dL})$ & 15.2 & 12.4 & 13.4 & 14.3 \\
\hline $\operatorname{TWC}\left(10^{3} / \mu \mathrm{L}\right)$ & 8.89 & 10.2 & 9.16 & 7.36 \\
\hline $\operatorname{PLT}\left(10^{3} / \mu \mathrm{L}\right)$ & 299 & 261 & 306 & 320 \\
\hline Lymph \# $\left(10^{3} / \mu \mathrm{L}\right)$ & 1.63 & 1.21 & 1.74 & 1.61 \\
\hline Mono \# $\left(10^{3} / \mu \mathrm{L}\right)$ & 6.3 & 7.9 & 6.33 & 4.84 \\
\hline Neu \# $\left(10^{3} / \mu \mathrm{L}\right)$ & 0.67 & 0.7 & 0.76 & 0.58 \\
\hline $\mathrm{Na}(\mathrm{mmol} / \mathrm{L})$ & 138 & 137 & 139 & 141 \\
\hline $\mathrm{K}(\mathrm{mmol} / \mathrm{L})$ & 3.5 & 3.3 & 3.8 & 3.7 \\
\hline $\mathrm{Cl}(\mathrm{mmol} / \mathrm{L})$ & 97 & 100 & 99 & 103 \\
\hline Urea $(\mathrm{mmol} / \mathrm{L})$ & 2.8 & 2.6 & 2.9 & 2.4 \\
\hline Creatinine $(\mu \mathrm{mol} / \mathrm{L})$ & 38 & 49 & 48 & 49 \\
\hline $\mathrm{TB}(\mu \mathrm{mol} / \mathrm{L})$ & 17 & 17 & 10 & 12 \\
\hline $\mathrm{DB}(\mu \mathrm{mol} / \mathrm{L})$ & 5.4 & 5.34 & 3.4 & 4.3 \\
\hline AST (U/L) & 22 & 16 & 21 & 17 \\
\hline $\operatorname{ALT}(\mathrm{U} / \mathrm{L})$ & 14 & 10 & 12 & 14 \\
\hline $\mathrm{TP}(\mathrm{g} / \mathrm{L})$ & 84 & 70 & 72 & 73 \\
\hline $\mathrm{Alb}(\mathrm{g} / \mathrm{L})$ & 48 & 40 & 45 & 44 \\
\hline Glob (g/L) & 36 & 30 & 27 & 29 \\
\hline $\operatorname{ALP}(\mathrm{U} / \mathrm{L})$ & 63 & 56 & 60 & 58 \\
\hline $\mathrm{LDH}(\mathrm{U} / \mathrm{L})$ & 529 & 347 & 505 & 386 \\
\hline CPK (U/L) & 59 & 53 & 51 & 47 \\
\hline CKMB (U/L) & 36 & 16 & 33 & 14 \\
\hline $\mathrm{Ca}(\mathrm{mmol} / \mathrm{L})$ & 2.52 & & 2.28 & 2.25 \\
\hline $\mathrm{Mg}(\mathrm{mmol} / \mathrm{L})$ & 0.84 & & 0.83 & 0.79 \\
\hline Po4 (mmol/L) & 1.12 & & 1.31 & 1.19 \\
\hline $\mathrm{PT}(\mathrm{s})$ & & 12.9 & & \\
\hline INR & & 1.0 & & \\
\hline APTT (s) & & 38.5 & & \\
\hline
\end{tabular}

case 1, her symptoms suggestive of miscarriage started around the same time when she experienced mild upper respiratory tract infection which resolved spontaneously. However, she was screened later given her exposure history to her colleague who was diagnosed to have COVID-19 infection. For case 2, she likely has been exposed at least 2 to 3 weeks prior to her diagnosis of COVID-19 infection as her rapid antibody test showed presence of IgG antibody to SARS-CoV-2. Therefore, she likely has acquired COVID-19 infection prior to her miscarriage.

Vertical transmission of viral infection can occur during intrauterine life via trans-placenta, delivery via ingestion or aspiration of cervicovaginal secretions and postpartum via breastfeeding. COVID-19 infection was associated with a relatively higher rate of preterm birth, preeclampsia, caesarean delivery and perinatal death. However, there have been no published cases of clinical evidence of vertical transmission [2].

ACE2 is determined as the cellular entry receptor for SARS-CoV-2. The placenta and decidua are the main

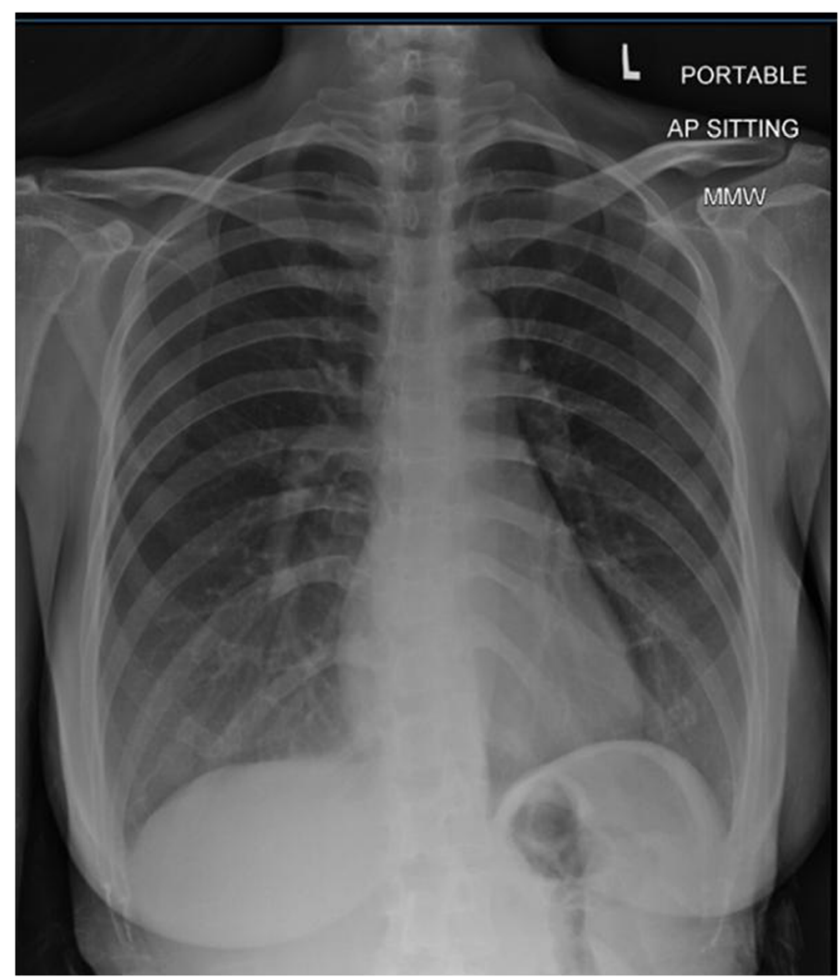

Fig. 2 Chest X-ray for case 2 on 18 April 2020 - no active lung lesion

maternal-foetal interface during pregnancy, and virus receptor expression in the placenta and decidual cells may play an important role in promoting transmission of SARS-CoV-2. Thirty-two cell types were observed from single cell transcriptome data sequenced by $\times 10$ genomics of early placenta (6 14 gestational weeks), of which four main cell types expressed ACE2 gene, namely, stromal cells (dS) and perivascular cells (dP) in decidua and villous cytotrophoblast (VCT) and syncytiotrophoblast (SCT) in placenta. The high expression of ACE2 in these cells suggests that the placenta has the potential to be infected by SARS-CoV-2 and may cause placenta dysfunction and pregnancy complications [4].

Of both cases, only the first case was prescribed with hydroxychloroquine, which is a molecule with extensive safety data during pregnancy. It was started after the onset of symptoms for miscarriage and is thus deemed unlikely to be the cause of the miscarriage. The second case was, on the other hand, not prescribed with any medication.

As there was no reported rate of vertical transmission of SARS-CoV-2 during the first trimester, as well as its outcome, we reviewed studies done for SARS-CoV in pregnancy. In one study, it was noted that four out of seven (57\%) women presented during first trimester sustained spontaneous miscarriage, likely attributed to hypoxia caused by SARS-related acute respiratory illness [5]. Interestingly, there have been no documentation of hypoxic episodes for both our cases during their inpatient monitoring. Thus, we concluded that it was not disease severity of SARS-CoV-2 infection that resulted in first trimester miscarriage in our patients. 
There was to date no reported data on first trimester pregnancy outcomes in MERS-CoV infected women as well. However, MERS-CoV infection was associated with adverse pregnancy outcomes resulting in maternal death, still birth as well as neonatal death shortly post-delivery [3].

However, we were unable to proof if the occurrences of miscarriage were due to occurrence of chromosomal problems which could be one of the causes which was unrelated to COVID-19 infection.

Both cases have missed miscarriage diagnosed clinically, supported by ultrasonographic evidence, prior to being diagnosed with COVID-19 infection. This could happen in those who were relatively asymptomatic or manifested mild symptoms of COVID-19 infection. However, the cause of the miscarriage was unknown, and SARS-CoV-2 infection as the causal factor could not be completely ruled out. We could not show direct evidence to suggest vertical transmission in our cases. More clinical studies will be needed to clearly establish the effect and co-relation of SARS-CoV-2 infection on pregnancy outcome, in all three trimesters. We would like to alert the physicians to take necessary investigations and infection control precautions when reviewing cases in COVID-19 era.

Acknowledgements We would like to thank our colleagues from the Obstetrics and Gynaecology Department, Sarawak General Hospital, for co-managing this patient. We would also like to express our deepest gratitude to the Laboratory in University Malaysia Sarawak (UNIMAS) and Pathology Unit of Sarawak General Hospital for valuable investigation support.

\section{Compliance with Ethical Standards}

Conflict of Interest The authors declare that they have no conflict of interest.
Ethical Approval This article does contain studies with human participant. All procedures performed in studies involving human participants were in accordance with the ethical standards of the institutional and/or national research committee and with the 1964 Helsinki declaration and its later amendments or comparable ethical standards.

Informed Consent Informed consent was obtained from all individual participants included in the study.

\section{References}

1. Knight M, Bunch K, Vousden N, Morris E, Simpson N, Gale C, et al. Characteristics and outcomes of pregnant women hospitalised with confirmed SARS-Cov-2 infection in the UK: a national cohort study using the UK Obstetric Surveillance System (UKOSS). 2020. https:// doi.org/10.1101/2020.05.08.20089268.

2. Di Mascio D, Khalil A, Saccone G, Rizzo G, Buca D, Liberati M, et al. Outcome of coronavirus spectrum infections (SARS, MERS, COVID-19) during pregnancy: a systematic review and meta-analysis. 2020;2:100107. https://doi.org/10.1016/j.ajogmf.2020.100107.

3. Abdullah Assiri, Glen R. Abedi, Malak Al Masri, Abdulaziz Bin Saeed, Susan I. Gerber, John T. Watson, Middle East respiratory syndrome coronavirus infection during pregnancy: a report of 5 cases from Saudi Arabia, Clin Infect Dis, Volume 63, Issue 7, 1 2016, https://doi.org/10.1093/cid/ciw412, 951, 953.

4. Li M, Chen L, Zhang J, Xiong C, Li X. The SARS-CoV-2 receptor ACE2 expression of maternal-fetal interface and fetal organs by single-cell transcriptome study. PLOS ONE. 2020;15(4):e0230295. https://doi.org/10.1371/journal.pone.0230295.

5. Wong SF, Chow KM, Leung TN, Ng WF, Ng TK, Shek CC, et al. Pregnancy and perinatal outcomes of women with severe acute respiratory syndrome. Am J Obstet Gynecol. 2004;191:292-7. https:// doi.org/10.1016/j.ajog.2003.11.019.

Publisher's Note Springer Nature remains neutral with regard to jurisdictional claims in published maps and institutional affiliations. 